ORIGINAL RESEARCH

\title{
Prompting Patients with Poorly Controlled Diabetes to Identify Visit Priorities Before Primary Care Visits: a Pragmatic Cluster Randomized Trial
}

\author{
Michelle T. Vo, MPH' , Connie S. Uratsu, RN MS CNS ${ }^{7}$, Karen R. Estacio, BA ${ }^{7}$, Andrea Altschuler, $P h D^{7}$, \\ Eileen Kim, MD², Stacey E. Alexeeff, $P h D^{7}$, Alyce S. Adams, $P h D^{7}$, Julie A. Schmittdiel, PhD', \\ Michele Heisler, MD MPA ${ }^{3,4}$, and Richard W. Grant, MD, MPH ${ }^{7}$
}

'Division of Research, Kaiser Permanente Northern California, Oakland, CA, USA; ${ }^{2}$ Department of Medicine, Oakland Medical Center, Kaiser Permanente Northern California, Oakland, CA, USA; ${ }^{3}$ Department of Internal Medicine, University of Michigan, Ann Arbor, MI, USA; ${ }^{4}$ Center for Clinical Management Research, Ann Arbor VA, Ann Arbor, MI, USA.

BACKGROUND: Most patients with diabetes do not meet all evidence-based goals of care, and many patients report poor communication and lack of involvement in decision-making during primary care visits.

OBJECTIVE: To test the hypothesis that a "Pre-Visit Prioritization" secure email message could improve visit communication and glycemic control among patients with type 2 diabetes.

DESIGN: We conducted a pragmatic, provider-randomized, multi-site clinical trial from March 2015 to October 2016 across 30 primary care practices within Kaiser Permanente Northern California (KPNC), a large integrated care delivery system.

PARTICIPANTS: Eligible patients had at least 1 year of KPNC membership, type 2 diabetes with most recently measured hemoglobin Alc (HbAlc) $>=8.0 \%$, and were registered users of the KPNC online patient portal.

INTERVENTIONS: Patients in the intervention arm, upon booking an appointment, received a secure email through the KPNC online portal with a link to the EHR allowing them to submit their top one or two priorities prior to the visit. Control patients received usual care.

MAIN MEASURES: Glycemic control; change in HbAlc 6 and 12 months after the initial visit; patient-reported outcomes related to patient-provider communication and patient care experiences.

KEY RESULTS: During the study period, 1276 patients had at least one eligible visit. In post-visit surveys ( $n=$ 457), more intervention arm patients reported preparing questions for their visit (72\% vs 63\%, $p=0.048$ ) and being given treatment choices to consider $(81 \%$ vs $73 \%, p=$ 0.041). Patients in both arms had similar reductions in

Prior Presentations Partial results from this study were presented at the European Association for the Study of Diabetes $53_{r d}$ Annual Meeting, September 14, 2017.

Electronic supplementary material The online version of this article (https://doi.org/10.1007/s11606-018-4756-4) contains supplementary material, which is available to authorized users.

Received April 1, 2018

Revised September 20, 2018

Accepted November 13, 2018

Published online February 11, 2019
HbAlc over the 12 -month study period $(0.56 \% \pm 1.45 \%)$, with no significant differences between arms.

CONCLUSIONS: A "light touch" email-based pre-visit intervention resulted in improved measures of visit interaction but did not significantly improve glycemic control relative to usual care. Improving diabetes clinical outcomes through more effective primary care visits may require more intensive approaches to patient visit preparation.

\section{TRIAL REGISTRY: NCT02375932}

KEY WORDS: clinical trials; doctor-patient relationships; diabetes; primary care; health information technology.

$\mathrm{J}$ Gen Intern Med 34(6):831-8

DOI: $10.1007 / \mathrm{s} 11606-018-4756-4$

(C) Society of General Internal Medicine 2019

\section{INTRODUCTION}

Over 30 million people in the USA have diabetes, representing an annual health care cost of over $\$ 245$ billion dollars. ${ }^{1} \mathrm{~A}$ robust evidence base from clinical trials and large cohort studies provides clear guidelines for the clinical management of diabetes and associated risk factors. ${ }^{2}$ Despite gains in the quality of diabetes care in past decades, however, the majority of patients with diabetes still do not reach all goals of evidence-based management. ${ }^{3}$ Indeed, evidence suggests that improvements in the overall quality of diabetes care have now plateaued. ${ }^{4}$

Most patients with type 2 diabetes are managed in the primary care setting. Providing effective diabetes care during brief and complicated primary care visits remains an important challenge. ${ }^{5}$ Prior research has shown that there is insufficient time to address all preventative and chronic disease management care tasks. ${ }^{6-8}$ With too many tasks in too little time, patients and providers must inevitably prioritize how to use their time together. ${ }^{9}$ This prioritization can be a challenging task, particularly because some patients may be reluctant to voice relevant concerns (such as those related to mental or social health), ${ }^{10-12}$ or do so near the end of the visit. ${ }^{13}$

Recent research has focused on improving patient-provider communication and facilitating more effective shared decision- 
making. ${ }^{14,15}$ Patient-centered efforts to improve visit interactions are seen as important avenues to improving care but have often had limited dissemination due to the increased resources and cost needed to implement. ${ }^{16-18}$ We tested the hypothesis that providing a simple and inexpensive means for patients with inadequately controlled type 2 diabetes to identify and then notify their primary care physician (PCP) of their top one or two concerns prior to their primary care visit would lead to more effective visit interactions. We further hypothesized that improved shared decision-making and alignment of patient and provider priorities during these visits could, in turn, facilitate the necessary changes to improve diabetes control.

\section{METHODS}

\section{Study Design and Randomization}

We conducted the Pre-Visit Prioritization Study (ClinicalTrial. gov NCT02375932) from March 15, 2015, to October 30, 2016, with 1 year of clinical follow-up ending October 30, 2017. This pragmatic, two-arm, cluster-randomized trial was implemented with 1:1 random number sequence randomization at the provider level stratified by practice. We enrolled 146 PCPs from 30 primary care practices within Kaiser Permanente Northern California (KPNC), a non-profit integrated care delivery system providing care for over 260,000 members with diabetes. The distribution of member demographic and socioeconomic factors is diverse and similar to that of the area population. ${ }^{19}$

Each PCP provided informed consent. Prior to randomization, physicians reviewed and approved patients from a list of their potentially eligible patients (lists ranged from 5 to 52 patients). Patient eligibility criteria consisted of KPNC membership for at least 1 year, type 2 diabetes with most recently measured hemoglobin $\mathrm{A} 1 \mathrm{c}(\mathrm{HbA} 1 \mathrm{c})>=8.0 \%$, age 20 to 80 years, and registered user of the KPNC online patient portal used for secure electronic communication with physicians and other members of their health care team. During the study period, $73 \%$ of KPNC members with type 2 diabetes were registered users of the portal.

The Kaiser Foundation Research Institute Institutional Review Board (IRB) approved the waiver for written informed consent from patients of providers enrolled in our study. The rationale was twofold: (1) the intervention itself posed minimal patient risk (secure electronic messaging is a standard clinical practice, message recipients and content were approved by participating PCPs, and all clinical decisionmaking remained solely the responsibility of the patient's PCP) and (2) this pragmatic approach would improve generalizability of results by including a minimally selected population of "real-world" primary care patients.

\section{Intervention Design}

The rationale and design for the study have been described in detail elsewhere. ${ }^{20,21}$ Briefly, our premise was that patients with type 2 diabetes are increasingly complex and often have multiple medical and social concerns apart from their diabetes. For these patients, competing demands and lack of visit preparation may lead to less effective visit encounters. ${ }^{12,22}$ Our goal was to facilitate communication between a prepared patient who has had time before the visit to identify his/her priorities and an informed provider who is aware of the patient's care priorities at the beginning of the visit. ${ }^{23}$ Improved visit communication, in turn, would ultimately lead to better diabetes management due to addressing barriers to care and greater adherence to collaborative care plans.

\section{Intervention Implementation}

Eligible intervention arm patients received a "Pre-Visit Prioritization (PVP)" secure electronic email message sent by study staff soon after scheduling a primary care appointment. Most PVP email messages were sent within $24 \mathrm{~h}$ of the appointment being scheduled. Appointments were not restricted by visit type as long as they were with the patient's own PCP. The message thanked the patient for making the appointment, emphasized the importance of identifying concerns to discuss at the visit, and provided an embedded hyperlink to a form for the patient to select one or two priorities (see Table 1 for choices provided). Once the patient completed and submitted this electronic form, his or her chosen visit priorities (and a small amount of allowed free text) were stored within the electronic health record (Epic $®)$. These priorities became visible to the PCP on the day of the visit by being automatically uploaded into the provider's visit encounter form when opened during (or just prior to) the visit. For appointments scheduled more than 2 weeks in advance, a reminder email was sent the week prior to the visit to those patients who had not yet submitted their visit priorities. Control arm patients continued with usual care, which included a coordinated diabetes disease management program and as needed primary care visits.

\section{Study Outcomes}

Our primary clinical outcome was proportion of patients achieving HbA1c goal at 1 year comparing all patients in the

Table 1 Five Visit Priority Options and Examples Provided

\begin{tabular}{|c|c|}
\hline Priority & $\begin{array}{l}\text { Examples provided in the PVP } \\
\text { secure message }\end{array}$ \\
\hline $\begin{array}{l}\text { Diabetes-related } \\
\text { concerns }\end{array}$ & $\begin{array}{l}\text { Making lifestyle changes, blood sugar levels } \\
\text { too high or too low, numbness or pain in your } \\
\text { feet, diet or exercise goals }\end{array}$ \\
\hline $\begin{array}{l}\text { Important changes } \\
\text { in life }\end{array}$ & $\begin{array}{l}\text { Important changes at home or work, financial } \\
\text { problems, illness involving family or friends }\end{array}$ \\
\hline Medication concerns & $\begin{array}{l}\text { Side effects, cost of medicines, not filling a } \\
\text { prescription, or any changes you have made }\end{array}$ \\
\hline Mood/motivation & $\begin{array}{l}\text { Difficulty getting motivated to take care of } \\
\text { yourself, feeling anxious or depressed, } \\
\text { problems with alcohol or addiction }\end{array}$ \\
\hline $\begin{array}{l}\text { New/important } \\
\text { health issues }\end{array}$ & $\begin{array}{l}\text { Pain, poor sleep, sexual issues, trouble with } \\
\text { your usual activities. }\end{array}$ \\
\hline
\end{tabular}


intervention and control arms. We also investigated change in $\mathrm{HbAlc}$ levels. Eligible baseline $\mathrm{HbA1c}$ was defined as an $\mathrm{HbA} 1 \mathrm{c} \geq 8.0 \%$ measured most recently prior to a visit during the study period. Follow-up HbAlc results were collected over the 12 months post-visit. We used any results within 3 months (before or after) the 6-month and 12-month end points after the index visit for outcome assessment. By definition, providers could not be blinded to randomization status; however, collection and assembly of data for post-visit telephone surveys and analysis were masked to randomization status.

Our primary patient-reported outcomes were assessed using post-visit telephone surveys conducted in a subset of patients during the final 6-month period of the clinical trial. With IRB approval, we obtained patient informed consent for this portion of the study before administering a 15-min post-visit survey that included questions related to patient-provider communication and patient care experiences. ${ }^{24-29}$ We purposefully sampled intervention and control patients in a $2: 1$ ratio so that we could gather additional qualitative data from intervention patients after respondents completed the post-visit survey. Response rate was $58 \%$.

\section{Statistical Methods}

In our analysis of the post-visit surveys, ordinal responses were re-grouped into dichotomous responses and analyzed using $\chi^{2}$ tests. We examined change in HbA1c both as a continuous outcome and as a dichotomous outcome (improvement vs no improvement). Our target study size was based on $80 \%$ power to detect a difference of $0.25 \%$ in $\mathrm{HbA} 1 \mathrm{c}$ between study arms, a cluster size of 10 patients per provider, an intra-cluster correlation co-efficient of 0.01 , and less than $5 \%$ missing outcome data. Continuous outcomes were analyzed using linear mixed models with a random intercept for PCP to account for the correlation induced by the cluster randomized design. Dichotomous outcomes were analyzed using generalized linear mixed models with a logit link and a random intercept for PCP. We also examined differences between study arms in time to $\mathrm{HbA} 1 \mathrm{c}$ control, defined as $\mathrm{HbA} 1 \mathrm{c}<8.0 \%$, using the Kaplan-Meier analysis (SAS version 9.3, SAS Institute, Cary, NC). All primary analyses were based on "intention to treat" randomization status where the significance level was 0.05 and hypothesis testing was two-sided.

We conducted pre-planned sensitivity analyses of change in HbA1c stratified by pre-visit HbA1c level and by "on-treatment" use of the PVP secure message among intervention patients compared to controls. We also conducted exploratory analyses examining differences between treatment arms based on level of prior year secure electronic messaging and, at the physician level, years of practice. Within the treatment arm, we also explored changes in HbA1c stratified by whether or not the patient chose diabetes as a top priority for the visit.

\section{RESULTS}

\section{Recruitment and Enrollment}

Primary care physicians and their patients were recruited over a 12-week period (March 2015-June 2015) from 30 primary care practices at 13 different medical facilities across four Northern California counties. The study was presented during routine physician practice meetings attended by 162 primary care physicians, of whom 146 consented to enroll (90\% physician recruitment success rate). Enrolled providers excluded very few potentially eligible patients (60 of $2556,<2 \%$; Fig. 1).

\section{Provider Baseline Characteristics and Survey Results}

Enrolled PCPs had a mean age of $50.0 \pm 8.2$ years and had practiced for an average of $22.2 \pm 8.6$ years. More than half were women $(89 / 146,61 \%)$ and $14(10 \%)$ had joined KPNC within the past 5 years. Physician characteristics were similar between study arms (Table 2). Of the 146 PCPs enrolled in our study, 141 PCPs (97\%) completed a baseline five-question survey about their patients with elevated HbA1c. This survey showed that the majority of PCPs $(118 / 141,84 \%)$ reported "sometimes," "rarely," or "never" having enough time during visits with their diabetes patients with elevated HbAlc. Although most PCPs $(117 / 141,83 \%)$ reported that they "usually" or "always" elicited patients' one or two top concerns, only $57 \%$ (81/141) reported that their patients "usually" or "always" came prepared with one or two topics to discuss during their visit, and 39\% (55/141) reported that patients "usually" or "always" raised their concerns near the end of the visit.

\section{Patient Baseline Characteristics}

In total, 1276 unique patients (673 intervention patients; 603 control patients) attended at least one visit during the study period and were eligible for analysis. Patients had 2.0 \pm 1.5 visits with their primary care physician during the study period (2513 total visits; 1309 intervention visits; 1204 control visits). The patient study cohort was $56 \%$ male, $38 \%$ non-White race/ethnicity, with a mean age of $61.2( \pm 10.3)$ years and last measured HbAlc of $9.3 \%( \pm 1.3 \%)$. Patient characteristics were similar between study arms (Table 2).

\section{Uptake of the Intervention}

A pre-visit email was successfully sent by research staff for 1204 of 1309 (92\%) attended visits within the intervention arm. The primary reason for not sending a pre-visit email was insufficient time between booking and appointment (median = $10 \mathrm{~h}$ for visits without PVP emails sent).

Intervention patients opened $62 \%$ of pre-visit emails (746/ 1204). For one-third (34\%, 254/746) of opened emails, intervention patients submitted their visit priorities $(21 \%$ of pre-visit emails, 254/1204). Patients most frequently chose "New/important health issues" and "Diabetes-related concerns" as their visit 


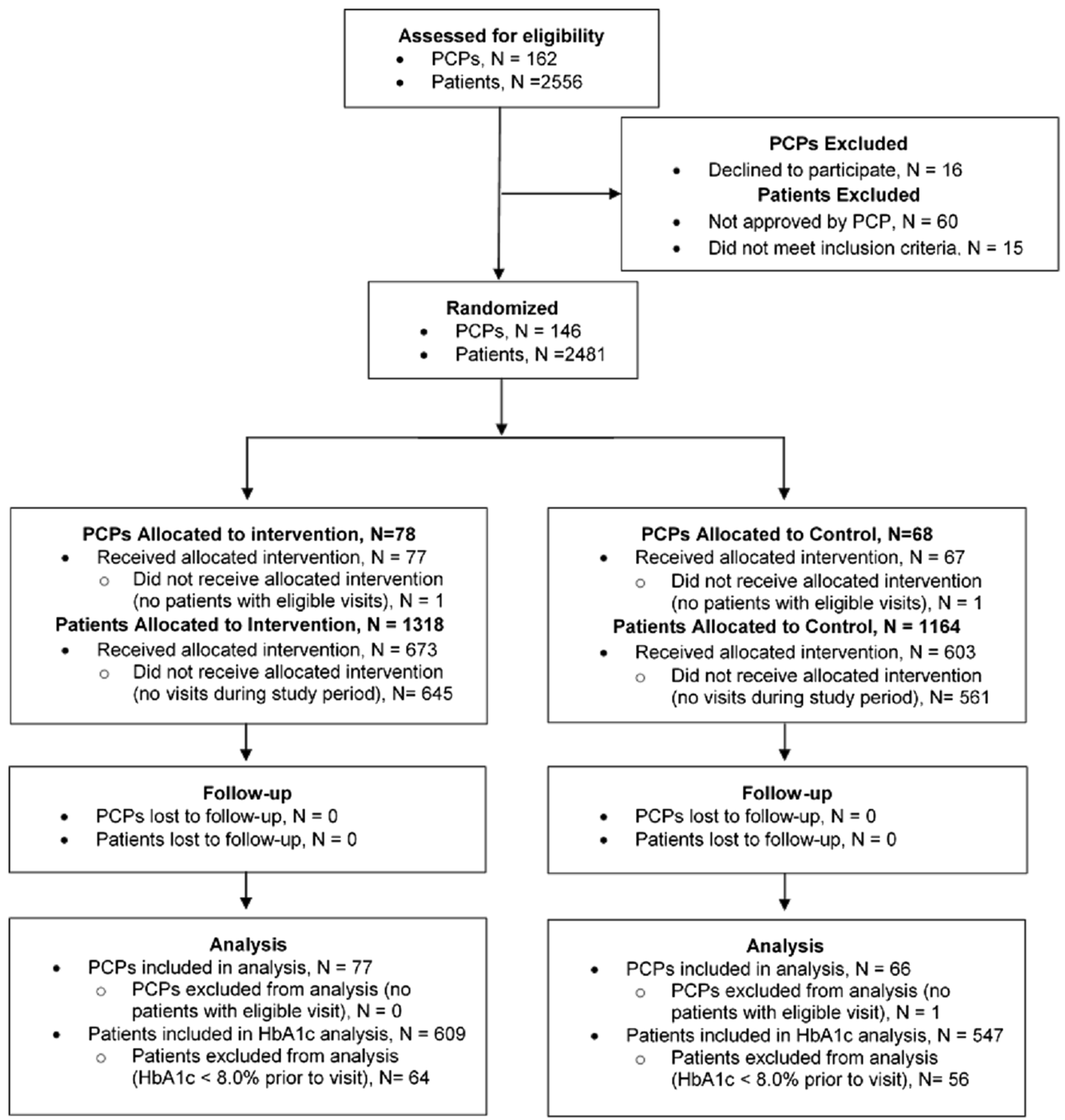

Figure 1 CONSORT diagram of patient and PCP flow.

priority (Online Appendix Table 1). Among patients submitting their visit priorities, nearly one-third $(64 / 205,31 \%)$ included concerns related to mood, motivation, or important life events.

\section{Effects on Visit Communication and Visit Interactions}

Post-visit patient surveys were administered over the final 6 months of the clinical trial, with 457 surveys completed (58\% response rate). Compared to control patients, patients who received the intervention were more likely to report preparing a list of questions for their doctor $(72 \%$ to $63 \%$, $p=0.048$ ). They were also more likely to report being given choices about their treatment to think about compared to control patients $(81 \%$ to $73 \%, p=0.041)$. Patients in both study arms rated their physicians very highly, with almost all respondents reporting that their physicians spent enough time with them $(96.9 \%)$ and listened carefully to their concerns $(99.7 \%)$ (Table 3). There were no other significant differences in other survey items between study arms. 
Table 2 Baseline Characteristics of Study Physicians and Their Eligible Randomized Patients $(n=1276)$

\begin{tabular}{|c|c|c|c|c|}
\hline Study physicians & All PCPs $(n=146)$ & Control $(n=68)$ & Intervention $(n=78)$ & $P$ \\
\hline Age, years (SD) & $50.0(8.2)$ & $50.9(8.4)$ & $49.2(8.0)$ & 0.21 \\
\hline Women, $n(\%)$ & $89(61.0)$ & $41(60.3)$ & $48(61.5)$ & 0.88 \\
\hline Years in practice (SD) & $22.2(8.6)$ & $23.3(8.7)$ & $21.2(8.4)$ & 0.13 \\
\hline *Baseline survey responses $(n, \%)$ & $n=141$ & $n=66$ & $n=75$ & \\
\hline Enough time during your visits & $23(16.3)$ & $12(18.2)$ & $11(14.7)$ & 0.57 \\
\hline Patients typically prepared with 1 or 2 topics & $81(57.4)$ & $39(59.1)$ & $42(56.0)$ & 0.71 \\
\hline Able to get through all the items on your agenda & $82(58.6)$ & $36(54.5)$ & $46(62.2)$ & 0.36 \\
\hline Patients raising their concerns near the end of the visit & $55(39.0)$ & $23(34.8)$ & $32(42.7)$ & 0.34 \\
\hline Study patients & All patients $(N=1276)$ & Control $(N=603)$ & Intervention $(N=673)$ & $P$ \\
\hline Women, $n(\%)$ & $564(44.2)$ & $268(44.4)$ & $296(44.0)$ & 0.87 \\
\hline Race/ethnicity, $n(\%)$ & & & & 0.09 \\
\hline African-American & $131(10.3)$ & $49(8.1)$ & $82(12.2)$ & \\
\hline Asian & $192(15.0)$ & $88(14.6)$ & $104(15.5)$ & \\
\hline Hispanic & $128(10.0)$ & $56(9.3)$ & $72(10.7)$ & \\
\hline Other & $39(3.1)$ & $18(3.0)$ & $21(3.1)$ & \\
\hline White & $786(61.6)$ & $392(65.0)$ & $394(58.5)$ & \\
\hline Age, mean (SD) & $61.2(10.3)$ & $61.2(10.4)$ & $61.2(10.3)$ & 0.94 \\
\hline Prescribed medicines, mean (SD) & $5.6(3.5)$ & $5.6(3.5)$ & $5.6(3.5)$ & 0.85 \\
\hline Baseline $\mathrm{HbA} 1 \mathrm{c}$, mean (SD) & $9.3(1.3)$ & $9.3(1.3)$ & $9.3(1.2)$ & 0.78 \\
\hline Baseline SBP, mean (SD) & $129.9(11.3)$ & $129.5(11.3)$ & $130.1(11.0)$ & 0.38 \\
\hline Baseline LDL, mean (SD) & $87.9(33.8)$ & $86.7(33.4)$ & $88.1(34.2)$ & 0.24 \\
\hline
\end{tabular}

PCP primary care physician

*Proportions are PCPs answering "usually" or "always" (choices were "never," "rarely," "sometimes," "usually," and "always") when considering a typical visit with patients with diabetes and elevated HbAlc

\section{Effects on Diabetes Control}

Study participants experienced an overall mean decrease in $\mathrm{HbA} 1 \mathrm{c}$ of $0.56 \% \pm 1.45 \%$ from baseline to 12 -month followup, and one-third of patients $(502 / 1156,43 \%)$ achieved HbA1c control (defined as $<8 \%$ ) with mean time to control of $147 \pm 100$ days. We found no statistically significant differences in changes in HbAlc at 6 or 12 months or in time to HbAlc $<8.0 \%$ between study arms (Table 4, Online Appendix Fig. 1). Differences between arms remained nonsignificant after stratifying by pre-visit HbAlc, frequency of prior year secure messaging, and after limiting intervention patients to those opening the Pre-Visit Prioritization secure message (Online Appendix Tables 2 and 3). In Cox proportional hazards models, time to control was significantly related to pre-visit HbA1c level (hazard ratio $0.60,95 \%$ CI 0.54-0.66, $p<0.01)$ but demographic characteristics known to be associated with glycemic control (gender, race/ethnicity, age) and intervention arm were not (Table 5, Online Appendix Fig. 1).

\section{Analyses of Patients in the Intervention Arm}

Intervention arm patients who opened their PVP secure messages had sent more electronic secure messages of any kind to $\mathrm{KPNC}$ in the prior year $(13.4$ vs $8.5, p<0.01)$ compared to intervention patients who did not open their PVP secure messages. There were no differences between PVP secure message openers and non-openers in age, gender, or race/ethnicity. Opening the PVP secure message was associated with more days between scheduling and attending the appointment ( 7.4 vs 3.3 days, $p<0.01$ ). Patients were also more likely to open emails sent by physician study staff than nonphysician study staff ( $70 \%$ vs $54 \%$ opened, $p<0.01$ ). Among intervention arm patients submitting visit priorities, we found no significant differences in HbAlc comparing patients who listed diabetes as a top visit priority vs patients who did not (Online Appendix Table 4).

\section{DISCUSSION}

A major challenge to the primary care of patients with type 2 diabetes is the limited amount of time available during visits to address the many competing demands faced by both patients and providers. $6,30,31$ Time limitations can lead to a lack of shared decision-making and lack of alignment between patient and physician priorities for the visit, with patient priorities often not being addressed. We conducted a pragmatic, physician-randomized, controlled trial to test the impact of a simple

Table 3 Patient Post-visit $(n=457)$ Survey Responses

\begin{tabular}{|c|c|c|c|}
\hline \multirow[b]{2}{*}{ Patient post-visit survey questions } & \multicolumn{3}{|c|}{ Freq. (\%) answering "Yes" } \\
\hline & Intervention $(n=291)$ & Control $(n=166)$ & $P$ value \\
\hline Did you prepare a list of questions for your doctor? & $210(72.2)$ & $105(63.3)$ & 0.05 \\
\hline Were you given choices about treatment to think about? & $236(81.1)$ & $121(72.9)$ & 0.04 \\
\hline Were you asked about any problems with medicines or their effects? & $232(79.7)$ & $120(72.3)$ & 0.07 \\
\hline Did your doctor spend enough time with you? & $282(96.9)$ & $158(95.2)$ & 0.35 \\
\hline Did your doctor listen carefully to you? & $290(99.7)$ & $164(99.8)$ & 0.27 \\
\hline
\end{tabular}


Table 4 Hemoglobin A1c Outcome

\begin{tabular}{|c|c|c|c|c|c|c|c|}
\hline & $N$ & Overall & $N$ & Control & $N$ & Treatment & $P$ \\
\hline \multicolumn{8}{|l|}{$\mathrm{HbA} 1 \mathrm{c}$} \\
\hline \multicolumn{8}{|l|}{ Mean $\pm \mathrm{SD}$} \\
\hline Pre-visit & 1156 & $9.39 \pm 1.32$ & 547 & $9.39 \pm 1.32$ & 609 & $9.40 \pm 1.32$ & 0.91 \\
\hline 6-month & 1052 & $8.91 \pm 1.48$ & 510 & $8.86 \pm 1.53$ & 542 & $8.96 \pm 1.43$ & 0.26 \\
\hline 12-month & 712 & $8.78 \pm 1.42$ & 340 & $8.80 \pm 1.47$ & 372 & $8.76 \pm 1.37$ & 0.69 \\
\hline \multicolumn{8}{|c|}{ Change in HbAlc } \\
\hline \multicolumn{8}{|c|}{ Mean $\pm \mathrm{SD}$} \\
\hline 6-month & 1052 & $-0.44 \pm 1.38$ & 510 & $-0.48 \pm 1.48$ & 542 & $-0.39 \pm 1.28$ & 0.31 \\
\hline 12-month & 712 & $-0.56 \pm 1.45$ & 340 & $-0.53 \pm 1.47$ & 372 & $-0.59 \pm 1.43$ & 0.59 \\
\hline \multicolumn{8}{|c|}{ Any decline in HbA1c (\%) } \\
\hline 6-month & 1052 & $644(61.2)$ & 510 & $313(61.4)$ & 542 & $331(61.1)$ & 0.92 \\
\hline 12-month & 712 & $473(66.4)$ & 340 & $221(65.0)$ & 372 & $252(67.7)$ & 0.44 \\
\hline
\end{tabular}

online tool to help patients prepare for their visits. This "light touch" intervention strategy improved several key patientreported measures related to the visit but did not lead to better glycemic control compared to control arm patients.

There are several possible explanations for the lack of impact of our intervention on the clinical endpoint of $\mathrm{HbA} 1 \mathrm{c}$ control. Glycemic control reflects a wide array of factors, including disease severity, medication intensity, and patient adherence to medicines and lifestyle changes. Helping patients and providers begin the visit knowing the patient's top concerns is likely an important first step towards improved diabetes control but, by itself, this strategy appears insufficient to ensure the timely cascade of steps necessary to lower $\mathrm{HbAlc}$ levels. Future efforts to improve glycemic control through previsit patient preparation may need to go beyond this first step of prioritization and onto empowering patients to more effectively raise and address concerns related to medication intensification and adherence, lifestyle changes, and other barriers or competing demands.

A second explanation is that many patients may already engage in pre-visit preparation and thus did not need the tool tested in this intervention. Indeed, in this insured population, we found in our post-visit phone surveys that many patients reported that they already prepared for visits. By conducting a pragmatic trial that optimized real-world applicability, we were unable to "screen out" patients who already prepared for visits. Other patients made appointments for acute concerns rather than to address diabetes care (as suggested by the high prevalence of "New/important health issues" as the top visit priority). Finding ways to identify and focus on the subset of patients in most need of pre-visit preparation might lead to more successful outcomes.

A third factor is that in modern health care systems, diabetes management is increasingly conducted by a team of health care providers that may include diabetes educators, pharmacists, nurses, and care managers. ${ }^{32}$ Focusing solely on primary care visits, while clearly a foundation of care, may not have taken full advantage of the opportunity to help patients in their interactions with other care team members. Moreover, the patient was given the opportunity to identify both diabetesrelated and diabetes-unrelated priorities. A more diabetescentric intervention may have had a greater impact on $\mathrm{HbAlc}$ control.

Finally, our intervention used online secure messages, an inexpensive and wide-reaching approach to patient contact. However, we found that many patients reported technical

Table 5 Cox Proportional Hazard of Achieving HbA1c $<8 \%$ During Study Period

\begin{tabular}{|c|c|c|c|c|}
\hline & Univariate HR (95\% CI) & $P$ & Multivariate HR (95\% CI) & $P$ \\
\hline \multicolumn{5}{|l|}{ Study arm } \\
\hline Control & 1 & & & \\
\hline Treatment & $0.90(0.74-1.09)$ & 0.29 & $0.91(0.76-1.10)$ & 0.34 \\
\hline Pre-visit a1c & $0.58(0.52-0.63)$ & $<0.01$ & $0.60(0.54-0.66)$ & $<0.01$ \\
\hline \multicolumn{5}{|l|}{ Race } \\
\hline White & 1 & & & \\
\hline Asian & $0.65(0.49-0.86)$ & $<0.01$ & $0.75(0.56-0.99)$ & 0.05 \\
\hline African-American & $0.69(0.50-0.95)$ & 0.02 & $0.91(0.66-1.26)$ & 0.58 \\
\hline Hispanic & $0.82(0.60-1.11)$ & 0.20 & $1.16(0.85-1.60)$ & 0.36 \\
\hline Other & $1.07(0.66-1.75)$ & 0.79 & $1.36(0.83-2.24)$ & 0.22 \\
\hline \multicolumn{5}{|l|}{ Gender } \\
\hline Female & 1 & & & \\
\hline Male & $1.15(0.96-1.38)$ & 0.13 & $1.09(0.91-1.31)$ & 0.33 \\
\hline \multicolumn{5}{|l|}{ Age (years) } \\
\hline$<40$ & 1 & & & \\
\hline $40-49$ & $0.66(0.31-1.42)$ & 0.28 & $0.63(0.29-1.35)$ & 0.23 \\
\hline $50-59$ & $1.41(0.71-2.80)$ & 0.32 & $1.25(0.63-2.49)$ & 0.53 \\
\hline $60-69$ & $2.21(1.13-4.32)$ & 0.02 & $1.65(0.84-3.27)$ & 0.15 \\
\hline$\geq 70$ & $2.28(1.16-4.50)$ & 0.02 & $1.51(0.76-3.02)$ & 0.24 \\
\hline
\end{tabular}


difficulties with their computers or tended to ignore our study message because of the volume of other emails received from KPNC. To the extent that these issues contributed to our null findings, these results demonstrate the potential value of combining technology with human interactions to achieve more robust impacts on patient care.

Results from patient and provider surveys partially confirmed key elements of our hypotheses for the intervention model. Provider baseline surveys clearly supported our premise that providers are pressed for time and perceive that their patients are often unprepared or leave important concerns to the end of the visit. Similarly, many of our patient respondents endorsed the value of tools to prepare for their primary care visits. Among patients submitting their priorities, nearly onethird included "non-medical" concerns related to mood, motivation, or important life events - issues that are often perceived as competing demands that may complicate standard diabetes management and directly impact diabetes care.

While prior research has shown the value of pre-visit preparation, ${ }^{33,34}$ these interventions have rarely been widely adopted in "real-world" settings despite promising initial results. We chose to implement a large pragmatic trial rather than a smaller more intensive intervention to more closely approximate the type of change that can be implemented across a broad range of practices and systems. Pragmatic trials maintain the rigor of randomization but seek to have broadly inclusive eligibility criteria and to measure outcomes of relevance to patients. ${ }^{35-37}$ By taking a less resource-intensive approach, our strategy had the potential to be more widely adopted by care systems and to benefit a larger segment of the patient population without imposing undue burdens on clinicians or care systems. The limitation of this approach is that greater patient inclusiveness came at the cost of less restrictive patient selection. Another study limitation was our setting in a highly functioning integrated delivery system with multiple programs targeting patients with poor glycemic control. KPNC leverages population-based team care and routinely achieves nation-leading success in managing patients with diabetes, as shown in the improvements in $\mathrm{HbAlc}$ achieved by patients in both arms in our study. Incremental improvement in such a highly functioning system is often more difficult than in settings where diabetes care is less well organized.

Our pragmatic randomized trial demonstrated that a light touch intervention directed towards patients before their primary care visits has the potential to improve visit interactions by helping patients identify and communicate their top visit priorities at the start of the visit. Further work is needed to translate this model into one that can directly improve clinical outcomes. Incremental advances could include using the pre-visit period to also help patients define care goals and articulate addressable barriers to making changes in care. More dramatic improvements in the current quality of diabetes care may require radical changes beyond incremental improvements at the margins of existing care.
Corresponding Author: Richard W. Grant, MD, MPH; Division of Research, Kaiser Permanente Northern California, 2000 Broadway, Oakland, CA 94612, USA (e-mail: Richard.W.Grant@KP.org).

Author Contributions All contributing individuals met requirements for authorship of this manuscript.

Funding Information This work is supported by the National Institute of Diabetes and Digestive and Kidney Diseases (R01DK099108, P30DK092926, and K24DK109114).

\section{Compliance with Ethical Standards:}

The Kaiser Foundation Research Institute Institutional Review Board (IRB) approved the waiver for written informed consent from patients of providers enrolled in our study.

Conflict of Interest: The authors declare that they do not have a conflict of interest.

Publisher's Note Springer Nature remains neutral with regard to jurisdictional claims in published maps and institutional affiliations.

\section{REFERENCES}

1. Centers for Disease Control and Prevention. Diabetes Report Card 2017. Atlanta: Centers for Disease Control and Prevention, US Dept of Health and Human Services; 2018.

2. Grant RW, Kirkman MS. Trends in the Evidence Level for the American Diabetes Association's "Standards of Medical Care in Diabetes" from 2005 to 2014. Diabetes Care. 2015;38:6-8.

3. Ali MK, Bullard KM, Saaddine JB, Cowie CC, Imperatore G, Gregg EW. Achievement of Goals in U.S. Diabetes Care, 1999-2010. N Engl J Med. 2013;368:1613-24.

4. Shahraz S, Anastassios, G. P., Saadati, M., Thomas, C.P., Lundquist, C. M., Kent, D. M. Change in Testing, Awareness of Hemoglobin Alc Result, and Glycemic Control in US Adults, 2007-2014. JAMA. 2017;318:1825-7.

5. Schneider KM, O'Donnell BE, Dean D. Prevalence of multiple chronic conditions in the United States' Medicare population. Health Qual Life Outcomes. 2009; 7:82.

6. Abbo ED, Zhang $\mathbf{Q}$, Zelder M, Huang ES. The increasing number of clinical items addressed during the time of adult primary care visits. $\mathrm{J}$ Gen Intern Med. 2008;23:2058-65.

7. Barnes CS, Ziemer DC, Miller CD, et al. Little time for diabetes management in the primary care setting. Diabetes Educ. 2004;30:126-35.

8. Ostbye T, Yarnall KS, Krause KM, Pollak KI, Gradison M, Michener JL. Is there time for management of patients with chronic diseases in primary care? Ann Fam Med. 2005;3:209-14.

9. Tai-Seale $\mathbf{M}, \mathbf{M c G u i r e} \mathbf{T G}, \mathbf{Z h a n g} \mathbf{W}$. Time allocation in primary care office visits. Health Serv Res. 2007;42:1871-94.

10. Bohlen K, Scoville E, Shippee ND, May CR, Montori VM. Overwhelmed patients: a videographic analysis of how patients with type 2 diabetes and clinicians articulate and address treatment burden during clinical encounters. Diabetes Care. 2012;35:47-9.

11. Adams JR, Elwyn G, Legare F, Frosch DL. Communicating with physicians about medical decisions: a reluctance to disagree. Arch Intern Med. 2012;172:1184-6.

12. Barry CA, Bradley CP, Britten N, Stevenson FA, Barber N. Patients' unvoiced agendas in general practice consultations: qualitative study. BMJ. 2000;320: 1246-50.

13. Kowalski C, McQuillan DB, Chawla N, et al. "The Hand on the Doorknob': A Qualitative Study of Preparation, Prioritization, and Agenda Setting by Complex Patients and Their Physicians during Primary Care Visits. J Am Board Fam Med. 2018; 31(1):29-37.

14. Heisler M, Bouknight RR, Hayward RA, Smith DM, Kerr EA. The relative importance of physician communication, participatory decision making, and patient understanding in diabetes self-management. J Gen Intern Med. 2002;17:243-52. 
15. Peek ME, Wilson SC, Gorawara-Bhat R, Odoms-Young A, Quinn MT, Chin MH. Barriers and facilitators to shared decision-making among African-Americans with diabetes. J Gen Intern Med. 2009;24:1135-9.

16. Rodriguez HP, Anastario MP, Frankel RM, et al. Can teaching agendasetting skills to physicians improve clinical interaction quality? A controlled intervention. BMC Med Educ. 2008;8:3.

17. Dwamena F, Holmes-Rovner M, Gaulden CM, et al. Interventions for providers to promote a patient-centred approach in clinical consultations. Cochrane Database Syst Rev. 2012;12:CD003267.

18. Schoenthaler A, Kalet A, Nicholson J, Lipkin M, Jr. Does improving patient-practitioner communication improve clinical outcomes in patients with cardiovascular diseases? A systematic review of the evidence. Patient Educ Couns. 2014;96:3-12.

19. Karter AJ, Moffet HH, Liu J, et al. Achieving good glycemic control: initiation of new antihyperglycemic therapies in patients with type 2 diabetes from the Kaiser Permanente Northern California Diabetes Registry. Am J Manag Care. 2005; 11:262-70.

20. Grant RW, Adams AS, Bayliss EA, Heisler M. Establishing visit priorities for complex patients: A summary of the literature and conceptual model to guide innovative interventions. Healthcare. 2013;1:117-22.

21. Grant RW, Uratsu CS, Estacio KR, et al. Pre-Visit Prioritization for complex patients with diabetes: Randomized trial design and implementation within an integrated health care system. Contemp Clin Trials. 2016;47:196-201.

22. Weiner SJ, Schwartz A, Weaver F, et al. Contextual errors and failures in individualizing patient care: a multicenter study. Ann Intern Med. 2010;153:69-75.

23. Wagner EH, Austin BT, Von Korff M. Organizing care for patients with chronic illness. Milbank Q. 1996;74:511-44.

24. Lorig KS, Stewart A, Ritter P, González V, Laurent D, Lynch J. Outcome Measures for Health Education and other Health Care Interventions. Thousand Oaks: Sage Publications; 1996.

25. Hargraves JL, Hays RD, Cleary PD. Psychometric properties of the Consumer Assessment of Health Plans Study (CAHPS) 2.0 adult core survey. Health Serv Res. 2003;38(6 Pt 1):1509-27.
26. Glasgow RE, Wagner EH, Schaefer J, Mahoney LD, Reid RJ, Greene SM. Development and validation of the Patient Assessment of Chronic Illness Care (PACIC). Medical Care. 2005;43:436-44.

27. Lerman CE, Brody DS, Caputo GC, Smith DG, Lazaro CG, Wolfson HG. Patients' Perceived Involvement in Care Scale: Relationship to attitudes about illness and medical care. J Gen Intern Med. 1990;5:29-33.

28. Maly RC, Frank JC, Marshall GN, DiMatteo MR, Reuben DB. Perceived efficacy in patient-physician interactions (PEPPI): Validation of an instrument in older persons. J Am Geriatr Soc. 1998;46:889-94.

29. Kristjansson E, Tugwell PS, Wilson AJ, et al. Development of the effective musculoskeletal consumer scale. J Rheumatol. 2007;34:1392400.

30. Morrison I. The future of physician's time. Ann Intern Med. 2000; 132:80-4.

31. Parchman ML, Romero RL, Pugh JA. Encounters by patients with type 2 diabetes-complex and demanding: an observational study. Ann Fam Med. 2006;4:40-5.

32. Schmittdiel JA, Gopalan A, Lin MW, Banerjee S, Chau CV, Adams AS. Population Health Management for Diabetes: Health Care System-Level Approaches for Improving Quality and Addressing Disparities. Curr Diab Rep. 2017;17:31.

33. Greenfield S, Kaplan S, Ware JE, Jr. Expanding patient involvement in care. Effects on patient outcomes. Ann Intern Med. 1985;102:520-8.

34. Greenfield S, Kaplan SH, Ware JE, Jr., Yano EM, Frank HJ. Patients' participation in medical care: effects on blood sugar control and quality of life in diabetes. J Gen Intern Med. 1988;3:448-57.

35. Thorpe KE, Zwarenstein M, Oxman AD, et al. A pragmatic-explanatory continuum indicator summary (PRECIS): a tool to help trial designers. J Clin Epidemiol. 2009;62:464-75.

36. Zwarenstein $\mathbf{M}$, Treweek $\mathbf{S}$, Gagnier JJ, et al. Improving the reporting of pragmatic trials: an extension of the CONSORT statement. BMJ. 2008;337:a2390.

37. Tunis SR, Stryer DB, Clancy CM. Practical clinical trials: increasing the value of clinical research for decision making in clinical and health policy. JAMA. 2003;290:1624-32. 